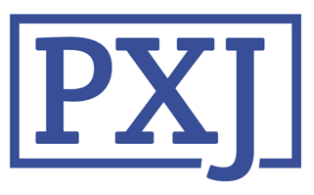

Patient Experience Journal

Volume 3 | Issue 1

Article 12

2016

\title{
Developing approaches to the collection and use of evidence of patient experience below the level of national surveys
}

\author{
Elizabeth J. Gibbons \\ University of Oxford \\ Chris Graham \\ Picker Institute Europe \\ Jenny King \\ Picker Institute Europe \\ Kelsey Flott \\ Picker Institute Europe \\ Crispin Jenkinson Professor \\ University of Oxford
}

See next page for additional authors

Follow this and additional works at: https://pxjournal.org/journal

Part of the Health and Medical Administration Commons, Health Policy Commons, Health Services Administration Commons, and the Health Services Research Commons

\section{Recommended Citation}

Gibbons EJ, Graham C, King J, Flott K, Jenkinson C, Fitzpatrick R. Developing approaches to the collection and use of evidence of patient experience below the level of national surveys. Patient Experience Journal. 2016; 3(1):92-100. doi: 10.35680/2372-0247.1118.

This Article is brought to you for free and open access by Patient Experience Journal. It has been accepted for inclusion in Patient Experience Journal by an authorized editor of Patient Experience Journal. 


\section{Developing approaches to the collection and use of evidence of patient experience below the level of national surveys}

\section{Cover Page Footnote}

Source of funding: Funding for this study was provided by the Department of Health Policy Research Programme and National Institute of Health Research (NIHR) Collaboration for Leadership in Applied Health Research and Care (CLAHRC -Oxford). Acknowledgements We would like to acknowledge the following collaborators: Jocelyn Cornwall, King's Fund Angela Coulter, Health Services Research Unit, University of Oxford Louise Locock, Department of Primary Care Health Sciences, University of Oxford Sophie Staniszewska, Royal College of Nursing Institute, University of Warwick. We thank the Patient Experience Advisory group- Department of Health for guidance and support. We also thank staff and patients at participating trusts involved in the research. Finally, we would also like to thank all of the patients who participated in cognitive interviews during the development of the questionnaire used in the research and those patients who provided feedback via the survey.

\section{Authors}

Elizabeth J. Gibbons, Chris Graham, Jenny King, Kelsey Flott, Crispin Jenkinson Professor, and Raymond Fitzpatrick Professor 


\title{
Developing approaches to the collection and use of evidence of patient experience below the level of national surveys \\ Elizabeth Gibbons, Nuffield Department of Population health, University of Oxford, Oxford, UK, elizabeth.gibbons@dph.ox.ac.uk Chris Graham, Picker Institute Europe, chris.graham@pickereurope.ac.uk \\ Jenny King, Picker Institute Europe, jenny.king@PickerEurope.ac.uk \\ Kelsey Flott, Picker Institute Europe, k.flott14@imperial.ac.uk. \\ Crispin Jenkinson, Nuffield Department of Population health, University of Oxford, Oxford, UK, crispin.jenkinson@dph.ox.ac.uk Ray Fitzpatrick, Nuffield Department of Population health, University of Oxford, Oxford, UK, raymond.fit:patrick@dph.ox.ac.uk
}

\begin{abstract}
National approaches to collecting patient feedback provide trust level information which although can provide a benchmark for trusts often doesn't provide information about specific services or patients experiences of pathways of care. This more granular level of data could be more informative for local service development and improvement. This research explored the feasibility and usefulness of such approaches. A conceptual model and standard questionnaire of patient experience was developed that might work across a range of services and pathways of care. Seven trusts were recruited as collaborating sites in which the model and survey instrument was tested. These were from different geographical locations and settings. The impact of the pilot and survey results on the improvement and development of services was evaluated. The service- line approach to capturing patient feedback was generally more feasible and considered of value for service improvement. The collection of patients' experiences across pathways of care was more challenging in terms of the development of the survey and interpretation of results. However, many sites identified specific actionable areas for improvement. This study has shown that it is possible to develop and apply a standardised survey in a range of services and provides evidence that a consistent unified approach to monitoring patient experiences is feasible. However several methodological problems are acknowledged such as the availability of resources and capacity for improvements to services and care. Evidence is now particularly needed to establish how best to produce positive impact from patient feedback.
\end{abstract}

\section{Keywords}

Patient experience; PREMs; pathways; service-lines; National Health Service; service improvement; patient centred care, quality of care

\section{Background}

Patient experience has assumed significant prominence in the measurement and improvement of health service performance. ${ }^{1}$ In the NHS, patient experience is regarded alongside patient safety and clinical effectiveness as one of three main components of service quality ${ }^{2}$ and is established in the Outcomes Framework ${ }^{3}$ as one of five domains used to assess performance of the NHS. The NHS patient survey programme has played a key role in building up a national picture of people's experience with trusts able to compare their results to others and monitor changes over time.

There are also many methods of collecting patient feedback at a local level: for example; many trusts use hand-held electronic devices to capture people's views in 'near-real-time' at the point of care. Trusts often develop bespoke surveys focusing of specific populations and/or services. Other approaches to gathering patients' experiences and feedback include kiosks, discovery interviews and using data derived from complaints. The introduction of the NHS Friends and Family Test (FFT) has also been an important policy driver to obtaining feedback about services and care - although this has limited value as a quantitative measure of performance ${ }^{4}$ and is promoted instead as a means of collecting narrative from a wide group of users. ${ }^{5}$

Despite all these different methods and approaches both nationally and locally, concerns have been expressed about whether the full potential of these are being realised. Analysis has shown that there is often little coherence to the wide range of disparate local activities, especially in terms of initiatives below the level of the whole trust or organisation. ${ }^{6}$ National collections, despite providing systematic and comparable data, are underexploited ${ }^{7}$ and not enough is being done locally to translate measures of patient experience into real improvements in the quality of care. $^{8}$

Patient Experience Journal, Volume 3, Issue 1 - Spring 2016

(C) The Author(s), 2016. Published in association with The Beryl Institute and Patient Experience Institute

Downloaded from www.pxjournal.org 
A study was therefore carried out to examine the scope for a more cohesive approach to monitoring patient experience at lower levels of healthcare organisations such as a specific unit, service or patient group. Specifically the study set out to develop and evaluate a simple, conceptually grounded and unified model for assessing patient experience and also to evaluate whether a standard measure could be used in a diverse range of settings.

It was postulated that, to develop mechanisms for monitoring patient experience at a more granular level, two approaches might be relevant. The first approach would focus on 'service lines' - a concept in healthcare settings dates back to the mid-1980s, rooted in healthcare management - particularly in acute hospital settings. In essence, service lines are specialised clinical areas with specific functional and operational remits, encouraged to develop cohesive management of a particular clinical area. ${ }^{?}$

The second approach focuses on 'pathways'. Whilst still placing importance on the role of services within an organisation, a pathway approach would, it was hypothesised, provide more detailed measurement of patient experience across organisational boundaries, particularly at points of transition in care between services. The pathway perspective is particularly relevant to take account of the journey of patients with long term conditions across diverse services over time. Recognising that patients' individual journeys are unique and unpredictable, the term 'pathways' was considered as a metaphor for the patient journey for the purposes of this study.

\section{Methods}

The study was designed to have three stages. In the first stage a conceptual model of patient experience was to be developed that might work across a range of services. The model was also intended to generate a standardised questionnaire that might be used across different service contexts. In the second stage a range of different services were to be recruited as collaborating sites in which the model and survey instrument could be tested. The third stage was to evaluate the impact of the pilot and survey results on the improvement and development of services.

Stage one: development of model and questionnaire In stage 1 the aim was to achieve an agreed definition of key domains of patient experience via literature review and synthesis, expert consultation, and exploration with key stakeholders.

Published and frequently used frameworks applied in patient experience surveys were reviewed and domains mapped with each other, including The NHS Patient Experience Framework; ${ }^{10}$ the Picker Institute's 'Principles of Patient Centred Care'; 11 the National Institute for Health and Care Excellence guidance and quality standard on patient experience in adult NHS services; ${ }^{12}$ World
Health Organization: Responsiveness of Health Care Systems ${ }^{13}$ and the Senses Framework. ${ }^{14}$

Generally, we found more similarity than difference between the various frameworks: it was clear that there was a reasonable degree of consensus on the domains that describe good patient experience. The final map of domains that emerged from analyses substantially converged with the NHS Patient Experience Framework, seen in Table 1.

The next step was to explore existing questionnaire items from major international surveys and group them under the identified conceptual domains. Over thirty surveys were reviewed including those developed for different care settings and health conditions. This mapping exercise resulted in a comprehensive database of survey items; over 100 items were compiled under the domain 'Information, communication and education' alone.

The database was reduced to a group of thirty items representing the domains. Items were excluded if they focused on 'functional'/ 'transactional' aspects of care, specific populations or settings, or on perceptions of satisfaction. Included in this list were a number of new items, developed by the research team where a good match could not be found from existing items. These thirty items were independently assessed by the wider collaborative group of research experts and the Patient and Public Involvement (PPI) panel involved in the project. This process resulted in twelve items plus demographic questions deemed suitable for use in assessing patient experience along different pathways of care or service lines.

To assess the content validity of the items, the draft questionnaire was tested with twenty members of the public who had experience of healthcare in the last year. In doing this we considered the cognitive process of responding in terms of the model described by Jabine (1984). ${ }^{15}$ With minor modifications, a core 13 -item questionnaire was developed that could be used in stage two.

\section{Stage two: recruitment and field-testing with collaborating sites.}

In stage two, pathway and service line approaches to collecting patient experience information were tested with seven collaborating sites using the questionnaire.

A pragmatic strategy was adopted to recruit collaborating sites, including use of established contacts, networking and nominations from our expert advisory group; the broad approach being purposive maximum variation sampling to identify sites for inclusion. It was intended that collaborating sites would cover different sectors, include urban and rural contexts, and be willing jointly to explore a 
Table 1. NHS Patient Experience Framework

\begin{tabular}{|c|}
\hline $\begin{array}{l}\text { Respect for patient-centred values, preferences, and expressed needs, including: cultural issues; the dignity, } \\
\text { privacy and independence of patients and service user; and shared decision making. }\end{array}$ \\
\hline Co-ordination and integration of care across the health and social care system. \\
\hline $\begin{array}{l}\text { Information, communication, and education on clinical status, progress, prognosis, and processes of care in order to } \\
\text { facilitate autonomy, self-care and health promotion. }\end{array}$ \\
\hline $\begin{array}{l}\text { Physical comfort including pain management, help with activities of daily living, and clean and comfortable } \\
\text { surroundings. }\end{array}$ \\
\hline $\begin{array}{l}\text { Emotional support and alleviation of fear and anxiety about such issues as clinical status, prognosis, and the impact of } \\
\text { illness on patients, their families and their finances. }\end{array}$ \\
\hline $\begin{array}{l}\text { Welcoming the involvement of family and friends, in decision-making and demonstrating awareness and } \\
\text { accommodation of their needs as care-givers. }\end{array}$ \\
\hline $\begin{array}{l}\text { Transition and continuity as regards information that will help patients care for themselves away from a clinical } \\
\text { setting, and co-ordination, planning, and support to ease transitions. }\end{array}$ \\
\hline $\begin{array}{l}\text { Access to care with attention for example, to time spent waiting for admission or time between admission and } \\
\text { placement in a room in an in-patient setting, and waiting time for an appointment or visit in the out-patient, primary } \\
\text { care or social care setting. }\end{array}$ \\
\hline
\end{tabular}

service-line or pathway approach to patient experience. Seven sites were included in the study (Table 2).

The approach to field-testing was co-designed with each participating site with the research group liaising with each site, participating in meetings to develop the methodology of recruitment and mode of administration; adapt the questionnaire to meet their requirements; and, in stage three, to discuss results. The research team maintained contact and support with staff members from the pilot sites throughout the fieldwork; feedback about the process was encouraged.

All direct costs of carrying out surveys in collaborating sites were met by the research group.

\section{Results}

A brief description of each collaborating site is provided, together with a summary of the methodology used, nature of the survey carried out and its results.

\section{A south coast of England stroke network - stroke services}

A collaboration with three hospital trusts in the South of England linked via a well-established Stroke Network provided leadership for this project. It was decided that the survey should focus on patients who were six months post discharge from hospital following a stroke. This represented a pathway approach to patient experience collection, taking account of their experiences across the many services received after discharge, such as community physiotherapy, occupational therapy, speech and language therapy, care from stroke specialist nurses, social care and care and support provided by voluntary organisations.
A wide range of patient experience feedback was already collected by staff in collaboration with the Stroke Network. Inpatient surveys which had been developed locally with specialist input from a speech and language therapist adopting an EasyRead format were administered by post 4 weeks post discharge. Results from these surveys were actioned and 'you said, we did' posters were displayed in the hospitals. In one trust, the FFT was administered at the point of discharge. Surveys on community services had also been carried out in the past but were logistically more problematic.

To carry out the proposed survey a wide array of stakeholders were consulted or actively involved. This included a consultant stroke physician, community services manager \& community lead for stroke, patient experience and customer services manager, consultant therapist, speech and language therapist, stroke specialist nurses, local authority representatives, voluntary organisations representatives, and a patient participation group.

Modifications were made to the core questionnaire by staff from the trusts, largely to encourage positive or negative comments about specific services. Free-text was encouraged for this purpose. The survey questionnaire was posted to patients' homes with a personalised letter from the consultant physician.

A total of 682 patients were eligible for inclusion in the study based on patients discharged during fieldwork. With a reminder to non-responders, the overall response rate was $48 \%$. 
Table 2. Collaborating sites

\begin{tabular}{|c|c|c|c|}
\hline Site & $\begin{array}{l}\text { Condition of focus/ } \\
n=\text { patients }\end{array}$ & $\begin{array}{l}\text { Pathway or } \\
\text { Service Line }\end{array}$ & $\begin{array}{c}\text { Method of } \\
\text { paper-based survey }\end{array}$ \\
\hline $\begin{array}{l}\text { A south coast of England } \\
\text { stroke network. Three } \\
\text { hospital trusts }\end{array}$ & Stroke $(n=684)$ & $\begin{array}{l}\text { Pathway- } \\
\text { community services } \\
\text { received } 6 \text { months } \\
\text { post discharge from } \\
\text { hospital }\end{array}$ & $\begin{array}{l}\text { Mail-out. } \\
\text { Three sample groups. } \\
\text { Response rate } 48 \%\end{array}$ \\
\hline $\begin{array}{l}\text { A teaching hospital trust } \\
\text { in the North of England }\end{array}$ & $\begin{array}{l}\text { Hip Fracture. } \\
\text { Four sample groups }(n=120)\end{array}$ & $\begin{array}{l}\text { Pathway- four cross } \\
\text { sectional surveys at } \\
\text { specific points of } \\
\text { the patient journey }\end{array}$ & $\begin{array}{l}\text { Mail-out and hand-out. } \\
\text { Response rate } 46 \%\end{array}$ \\
\hline $\begin{array}{l}\text { East of England Primary } \\
\text { Care practice }\end{array}$ & $\begin{array}{l}\text { All patients with } \\
\text { COPD on the practice register } \\
(n=174)\end{array}$ & $\begin{array}{l}\text { Pathway- } \\
\text { experiences of care } \\
\text { over the last year }\end{array}$ & $\begin{array}{l}\text { Mail-out. } \\
\text { One sample group. } \\
\text { Response rate } 72 \%\end{array}$ \\
\hline $\begin{array}{l}\text { Midlands community } \\
\text { trust }\end{array}$ & $\begin{array}{l}\mathrm{N}=1000 \text { patients } \\
\text { with Mental health problems } \\
\text { samples } \\
\text { from } 9 \text { Community Mental } \\
\text { Health Teams }\end{array}$ & $\begin{array}{l}\text { Pathway- } \\
\text { experiences over the } \\
\text { last year }\end{array}$ & $\begin{array}{l}\text { Mail-out. } \\
\text { One sample group. } \\
\text { Response rate } 26 \%\end{array}$ \\
\hline London acute trust & $\begin{array}{l}\text { Four service lines: COPD }(n=65) \\
\text { Speech \& Language Therapy } \\
(n=8) \text {, } \\
\text { Surgical Rehabilitation }(n=, 18) \\
\text { Sexual Health }(n=51)\end{array}$ & Service line & $\begin{array}{l}\text { Hand-out. } \\
\text { Four sample groups. } \\
\text { Response rates: } \\
\text { COPD 26\% } \\
\text { S\&L } 5.6 \% \\
\text { Rehab. } 30 \% \\
\text { SH } 8.5 \%\end{array}$ \\
\hline $\begin{array}{l}\text { Midlands community } \\
\text { health and social care }\end{array}$ & Adult social care $n=396$ & Service line & $\begin{array}{l}\text { Mail-out. Two sample groups. } \\
\text { Response rate } 15 \%\end{array}$ \\
\hline $\begin{array}{l}\text { Midlands teaching } \\
\text { hospital acute trust }\end{array}$ & $\begin{array}{l}\text { Musculoskeletal Triage Service } \\
\mathrm{n}=500 \text { (target) }\end{array}$ & Service Line & $\begin{array}{l}\text { Hand-out. Three sample groups. } \\
\text { Participation } \\
\text { and response rate } 29 \%\end{array}$ \\
\hline
\end{tabular}

Generally responses to questions were very positive, especially comments about specific staff members. Interesting differences about aspects of care emerged between trusts and specific positive feedback was obtained about an innovative early discharge scheme initiated at one trust. The main challenge in interpreting the survey was that questions invited respondents' views and experiences across services and staff wanted to link responses more clearly to specific services in order to identify actions. The main action that resulted was for the local Clinical Commissioning Group to consider treating the survey as a baseline against which repeated surveys in subsequent years could be assessed.

\section{A teaching hospital trust in the North of England - hip fracture pathway}

A large teaching hospital collaborated with the research group to review patients' experiences of services for hip fracture; this required a pathway perspective because of the range of services involved.
Locally, the trust used hand held devices to collect patient experience data, surveying approximately 250 patients per month. Comments cards completed by approximately 80 patients per month were another source of feedback. Results were regularly reported and discussed at ward, directorate and trust board level.

The Head of Patient Partnership, a consultant geriatrician, a hip fracture nurse, a therapy lead and matron for community rehabilitation formed the project group. It soon became clear that with the wide range of acute and community services involved in the overall management of patients after emergency admission for hip fracture, asking patients to comment on their whole journey would be challenging. Instead, using several independent crosssectional surveys were administered at the key stages of the hip fracture trajectory; acute orthopaedic ward, hip fracture ward, community rehabilitation and services at home. Other stages of the hip fracture pathway, such as emergency care, were discussed but were deemed less practical to cover. 
Additional items were added to the questionnaire for each stage of the pathway to cater for unique issues. For example, questions on the coordination of discharge planning services were included for community rehabilitation. Thirty questionnaires were sent out at each of the four stages of the pathway. No reminder mailings were sent. An overall response rate of $46 \%$ was achieved.

Results were distributed to all of the teams involved in the four stages. Areas for improvement and areas of excellence were highlighted with action plans developed, for example, an action to reduce the number of beds in the acute ward to improve staff-patient ratios. There was general agreement that generating evidence of patient experience across the hip fracture care pathway was beneficial to overall planning.

\section{An East of England Primary Care practice - chronic obstructive airways disease service}

A primary care practice in a semirural area in the East of England elected to carry out a survey of patients in the practice with chronic obstructive airways disease (COPD). The aim was to measure patients' experiences across the full range of services, including pulmonary rehabilitation, physiotherapy, specialist COPD nursing as well as hospital and primary care, and in this sense was testing a pathway approach.

Previous patient experience work in the practice included several small surveys of COPD patients across practices and a generic practice survey of patients in collaboration with the practice's Patient Participation Group. Based on the results small improvements were made to the environment: specifically, more parking was made available for patients to meet demand.

Staff involved in this research included: a GP, COPD specialist nurse, the practice nurse with a lead in COPD, receptionist/administrator, practice manager, a commissioner from the Clinical Commissioning Group and two patients.

It was agreed that a paper-based survey mailed out to home addresses of patients identified from the Quality Outcomes Framework (QOF) practice records as having COPD would be the most appropriate method. Two mailings were carried out which included a reminder mailing after four weeks. The practice was responsible for generating personalised covering letters. Posters displayed at the practice informed staff and patients about the study.

The core questionnaire developed by the research group was considered appropriate for this patient group and an EasyRead format was used. The practice wished to include the Medical Research Council (MRC) - Breathlessness scale to explore the relationship of responses to severity of symptoms/disability.
The overall response rate was $72 \%$. Over $80 \%$ of patients reported their experiences of COPD care over the last year to be excellent $(51 \%)$ or good $(33 \%)$. The majority of patients were treated with kindness and understanding. There were no striking differences in responses from patients with long-standing COPD compared to those diagnosed in the previous 5 years. The practice found the free-text material most interesting and informative. There were data quality issues with the MRC breathlessness scale and this made analysis of possible relationships between severity of symptoms and patient experience unreliable. However, this scale has primarily been developed for clinicians as a screening tool administered during consultations; it is not designed for self-completion by patients as was tested here.

Amongst specific actionable results, it was noted from item responses and qualitative free text that some patients would have liked their family to be more involved in decisions about their care. This was considered something that could be improved; the practice developed a series of specific steps to more actively engage carers. Further work was to be undertaken to improve and standardise information about COPD and to promote awareness of a local breathing problems support group.

\section{A Midlands community trust - adult community mental health services}

A pathway focused survey was used to assess service-users' experiences of their interaction with the range of services provided by adult Community Mental Health Teams. The Trust already had substantial experience of a diverse range of methods of assessing patient experience, including paper and electronic solutions to collecting feedback. Oversight of the current survey was provided by a small management-led group which included the Quality manager, Director of Nursing services and Occupation Therapy leads.

It was agreed that a paper-based survey would be mailed out to service users' home addresses with a reminder sent to non-responders after four weeks. A random sampling strategy was designed to obtain adequate responses from users of all nine community mental health teams in the trust, including those with different diagnoses and contact with services. As with other pathway-focused surveys in the study, and to provide additional granular evidence of specific services, respondents were invited to give their overall views on each of the service they accessed. Free text space was provided throughout.

A response rate of $26 \%$ was obtained from the 1000 questionnaires sent out. Most of the responses to items in the survey were positive and in many cases at the highest rating. Only $6 \%$ of respondents reported very poor experiences.

Free text responses were also generally positive although a minority expressed anger and frustration related to lack of understanding of their condition by healthcare 
professionals and unresponsiveness to crisis and needs. Some reported lack of consistency of care from different staff and lack of referral to specialist services. A minority also expressed feelings of suspicion about the purpose of the survey and concern that their answers would be linked to them as individuals.

Survey results were widely circulated to teams; staff responses identified actionable areas such as patient involvement in decisions and desire for greater involvement of family and carers in decisions.

\section{London acute trust - COPD, sexual health service, surgical rehabilitation and the speech and language service}

A large London trust providing both acute care and community chose to explore the experiences of patients across a variety of service lines.

The trust had a comprehensive approach to collecting patient experience data making use of near-real time feedback via electronic devices, paper-based and telephone surveys using its own library of questions and patient stories. Volunteers contribute to the collection of patient experience information. All activity is overseen by a trustlevel Patient Experience and Engagement Committee (PEEC) which monitors action plans emerging from surveys.

The trust team for the project included the head of patient experience, leads for sexual health services, adult speech \& language therapy, surgical rehabilitation and a nurse consultant. It was decided to carry out service line surveys of the COPD service (providing both hospital and community services), the sexual health service, the surgical rehabilitation service (also hospital and community services) and the speech and language service for inpatients. A selection of other services were interested in participating, but either had too few service users or not enough staff resources to administer a questionnaire.

It was decided that the most feasible method for administration was a postal survey to patients discharged over a defined period. A small number of service-specific items were also developed and agreed were added to the core questionnaire; for example the speech and language service wanted to address specific issues regarding services for communication and swallowing.

In total 1,050 questionnaires were posted to patients and an overall response rate of $14 \%$ was achieved. The low response rate did not come as a surprise to staff who cited the demographic characteristics of their users - such as youth in the sexual health survey and more generic deprivation and language problems of the London population - as contributors to the low number of returns.
Overall responses were positive; however only $34 \%$ felt that healthcare staff offered family, carers or friends the opportunity to be involved in decisions about their condition and treatment.

All four services fed back results to teams and expected to turn results into "you said, we did" report boards displayed to patients and the public to promote action.

\section{A Midlands community health and social care trust - community intervention and independent living services}

This large NHS community trust agreed to collaborate to examine experiences of adult social care, especially community intervention and independent living services.

Prior to this study, the trust mainly obtained feedback of experiences through a monthly survey implemented by staff on hand-held devices after home visits with results presented back to teams and localities.

The head of social work, two patient experience officers, and a resource manager for Personalisation and Quality comprised the trust's project group. It was decided to target service users of the community intervention and independent living services who had recently received a six week review. Understanding how the two services performed in comparison with each other was important for the trust.

Unlike the other collaborating sites, the trust decided not to use the core questionnaire developed for the project, instead using a locally developed adult social care instrument, which, whilst similar to the research study's core questionnaire, had items specifically on issues such as aids and social support in the home.

A response rate of $15 \%$ was obtained from the survey. Feedback and actions following from the survey could not be achieved within the timelines of the research study however plans for results to be fed in to the trust wide action planning were in place.

\section{A Midlands teaching hospital acute trust- musculoskeletal triage service}

A number of service models have been initiated in the NHS whereby musculoskeletal 'hubs' manage the demand from primary care to secondary services. Typically they provide triage, diagnostics, treatments or referral to secondary services. One such service run from an orthopaedic centre (with two satellite clinics) agreed to work with us to obtain patient experience evidence relating to their recently established 'hub'.

Prior to this project, in addition to the nationally required Friends and Family Test (FFT), and the NHS Inpatient Survey, interviews and real-time feedback via iPads had 
been used. The current project was led by a clinical director of services supported by the musculoskeletal triage manager. Information sheets about the project were distributed to other staff at the 'Hub'.

It was decided that the survey could be administered to attendees prior to leaving the hospital but a pre-paid envelope would be included should they wish to return the survey by post. Covering letters to the survey were personalised with the Clinical Director's electronic signature.

The research questionnaire was used with minimal adaptation but included the FFT. The survey was intended to reach 500 patients but only achieved a response rate of $29 \%$ with no responses from the two satellite sites.

Over $60 \%$ of responses were in the highest positive categories for most items. Patients felt they were given the right amount of relevant information, were involved in decisions, were encouraged to talk about their worries and fears and were treated with kindness and understanding. Patients also reported similar positive experiences related to coordination of care, physical needs being met and had confidence in staff. This was also supported in the free text comments. Furthermore, $72 \%$ of patients found the care they received helpful in dealing with the problem(s) they attended for.

By contrast patients reported in the free text, problems with the appointment system. The results, confirmed suspicions that the new booking system for this innovative hub was not working well. It was decided that more collaboration with primary care services was essential to improve methods for making appointments and increase understanding of the service worked.

\section{Stage 3: Discussion}

With the exception of one site, the diverse stakeholdershealth professionals, managers, patient representatives and commissioners accepted the study questionnaire as a sound basis with which to explore patient experience, with few significant modifications. The main modifications were the expansion of space to permit free-text elaboration of responses and, particularly where patients were invited to assess their experiences of care across a range of services, the opportunity to report service-specific experiences. Unsurprisingly the one site unable to use the core questionnaire elected to focus on social care issues and preferred an existing instrument with that focus.

The adoption of the questionnaire to develop and carry out surveys of patient groups using particular service-lines proved generally more straightforward taking advantage of existing staff resources, mechanisms to sample and recruit respondents, routes and audiences to feedback results, and processes to identify actionable issues. In these cases the new surveys constituted a more accessible evolution of existing practice - although they could also be seen as less ambitious and retaining a reliance on a service imposed view of patient experience.

By comparison, surveys to capture patients' experiences across diverse services, termed pathway-approaches, represented a greater departure from conventional approaches: accordingly, they were arguably more ambitious and certainly more challenging to implement. The difficulty was not in identifying populations to survey - for example, all patients with a condition in the primary care survey of patients with COPD, or all patients discharged from hospital over a given time period, as in the survey of patients with stoke. Rather, the challenge was in designing an appropriate survey instrument and then interpreting obtained results. In three of the pathway sites, the study explored the potential to use the core questionnaire to ask respondents to assess different domains of experience across the range of services that they received. It was recognised to be a potentially challenging task, both for patients to respond and for stakeholders to interpret findings. Mechanisms were incorporated into those surveys to allow respondents to provide free text detail or specify services resulting in good or bad experience. The fourth site, wishing to gain an overview of patients' experiences across all of the services involved in care for hip fracture, decided that patients would themselves not be able to remember or focus on the many different services experienced and settled for four separate cross-sectional surveys, aiming to build a picture of the patient pathway by taking consecutive, independent snapshots of experiences at key points along a 'typical' patient journey

All of the case studies pursuing a pathway approach were especially concerned about the problem of attributing experiences to any single service and subsequently take remedial action. This is effectively resolved in the hip fracture example, where separate cross-sectional surveys permit the direct attribution of results to providers in much the same manner as our service-line surveys: however, this came at the cost of undertaking four collections instead of one. Alternative solutions were explored in other sites, ranging from the inclusion of additional questionnaire items about specific services within a single survey, through to providing substantial freetext space to allow respondents to identify positive or negative experiences with specific services. The freetext comments helped provide a more vivid picture which supports previous research that found the sharing and facilitation of qualitative comments at team meetings with staff helps to stimulate interest in results. ${ }^{16}$

It was difficult to delineate impact of the survey on sites. The majority of sites identified specific plans or actions that flowed from the survey: for example, the commitment 
to improve staff/patient ratios in the hospital wards managing hip fracture, or the commitment to increase family and carer involvement in the case of primary care management of COPD. However, often specific actions in response to the survey were modest. It is difficult given the design of this study to be precise about the attribution of impact because in most sites significant and varied monitoring of patient experience was already the norm. There was good intention to disseminate results to other stakeholders within the sites' organisations, including patient groups, as well as repeat the survey; the impact of that feedback is not known within this study.

This study provides evidence that a consistent unified approach to monitoring patient experiences is feasible. However several methodological problems need to be acknowledged. Firstly, it would have been preferable to invest more resources in establishing measurement properties of the core questionnaire such as reliability and validity. It might also have been an opportunity to examine concurrent trends such as the NHS-wide introduction of the FFT but this was considered beyond the remit of the study by stakeholders who considered the FFT as effectively mandated and not requiring evaluation. Secondly, the selection of collaborating sites was pragmatic; whilst it did result in a diversity of types of organisation and patient groups surveyed, it is difficult to rule out the possibility that selection bias operated to influence results, for example in favour of the feasibility of conducting the research. . A problem with a study such as this one involving substantial co-design and collaboration with partners was that there was limited scope for controlled study design to facilitate more accurate estimation of the effects of specific variables. Moreover all sites were quite conservative in their use of recently introduced methods such as hand held devices as part of their collaboration with the study so that there was no scope to examine such innovations. Lastly, the majority of the surveys carried out with collaborators had relatively low response rates. It is of interest that far the most favourable response rate was obtained in a primary care population where longer term relationships between patients and providers may be expected; although we must be tentative in drawing conclusions from this, as the patient group also differed in other demographic characteristics from those at other pilot sites. Some of the sites preferred a personalised approach to the mailing of the survey; personalised covering letters for example. Personalisation is considered to be a useful aid to increasing response rates ${ }^{17}$ and this may have impacted on higher response rates in the primary care setting. The same approach adopted by community stroke services site produced a lower response rate overall, but this was slightly higher than the trust's own survey collection of inpatient experience. Disentangling factors associated with increasing response rates to postal surveys are inherently problematic, particularly within the context of a study such as this one that involved a broad range of respondent groups and different geographic areas.

\section{Conclusion}

The policy imperative to take account of patients' feedback will continue. If this is to translate into the development of improved services, this will need to be felt and acted on at the level of specific services as well as at higher levels within organisations. Several factors may stimulate improvement in methods used to assess patient experience at the level of specific services. Providers, healthcare professionals and the public may increasingly want to compare results across services within the trust. It may also become increasingly unacceptable to stakeholders to carry out such surveys with ad-hoc or poorly developed questionnaires. Finally, particularly as services address the needs of patients with multiple complex long term conditions, it may be necessary to assess patients' and users' experiences across multiple services; policy drivers continue to focus on the development of strategies to better integrate health and social care services.

This study has shown that it is possible to develop and apply a standardised survey in a range of services concerned with acute and long term conditions. It has been argued that resources and capacity on the part of services to support such developments and applications is weak and may require strengthening at local or regional level [8]. It was certainly the case that - despite significant enthusiasm and commitment to patient experience -staff time in collaborating sites was largely taken up with responding to existing national commitments such as the FFT to monitoring patient experience, and there was limited flexibility to measure and use patient experience beyond these.

The approach tested in the current study is intended to complement the many other approaches to listening and responding to patient experience based on other kinds of feedback. Evidence is now particularly needed to establish how best to produce positive impact from patient feedback of whatever kind. ${ }^{18}$ With all such developments combined, enormous progress is possible to make services fully patient- and user-centred.

\section{Source of funding}

Funding for this study was provided by the Department of Health Policy Research Programme and National Institute of Health Research (NIHR) Collaboration for Leadership in Applied Health Research and Care (CLAHRC -Oxford). 


\section{Acknowledgements}

We would like to acknowledge the following collaborators:

- Jocelyn Cornwall, King's Fund

- Angela Coulter, Health Services Research Unit, University of Oxford

- $\quad$ Louise Locock, Department of Primary Care Health Sciences, University of Oxford

- $\quad$ Sophie Staniszewska, Royal College of Nursing Institute, University of Warwick.

We thank the Patient Experience Advisory groupDepartment of Health for guidance and support. We also thank staff and patients at participating trusts involved in the research. Finally, we would also like to thank all of the patients who participated in cognitive interviews during the development of the questionnaire used in the research and those patients who provided feedback via the survey.

\section{References}

1. Anhang, R., Elliott, M. N., Zaslavsky, A. M., Hays, R. D., Lehrman, W. G., Rybowski, L., Cleary, P.D. (2014). Examining the Role of Patient Experience Surveys in Measuring Health Care Quality. Medical Care Research and Review, 1-33. doi:10.1177/1077558714541480

2. Department of Health (2008). High Quality Care For All: NHS Next Stage Review final report. London: The Stationery Office

3. Department of Health. (2012a). NHS Outcomes Framework 2013 to 2014. Retrieved from https://www.gov.uk/government/publications/nhsoutcomes-framework-2013-to-2014

4. Sizmur, S., Graham, C., \& Walsh, J. (2015). Influence of patients' age and sex and the mode of administration on results from the NHS Friends and Family Test of patient experience. Journal of Health Services Research \& Policy, 20(1), 5-10. http://doi.org/10.1177/1355819614536887

5. NHS England. (2014, July). The Friends and Family Test review. Retrieved from http://www.england.nhs.uk/ourwork/pe/fft/fft-testreview/

6. Cornwell, J., \& Goodrich, J. (2011, January). Challenges for improving patients' experiences of health care. Journal of Health Services Research \& Policy, 16(1), 1-2.

7. DeCourcy, A., West, E., \& Barron, D. (2012). The National Adult Inpatient Survey conducted in the English National Health Service from 2002 to 2009: how have the data been used and what do we know as a result? BMC Health Services Research, 12(1), 71. http://doi.org/10.1186/1472-6963-12-71
8. Coulter, A., Locock, L., Ziebland, S., \& Calabrese, J. (2014, March). Coulter A, Locock L, Ziebland S, Calabrese J. Collecting data on patient experience is not enough: they must be used to improve care. BMJ. 2014 Mar 26;348. BMJ. doi:http://dx.doi.org/10.1136/bmj.g2225

9. Monitor. (2009). Service-line management: an introduction for NHS foundation trusts. Retrieved from

https://www.gov.uk/government/publications/servi ce-line-management-an-introduction-for-nhsfoundation-trusts

10. Department of Health. (2012b, February 22). NHS Patient Experience Framework. Retrieved September 2, 2014, from https://www.gov.uk/government/publications/nhspatient-experience-framework

11. Picker Institute. (1987). Picker Principles of PatientCentered Care. Retrieved September 2, 2014, from http://pickerinstitute.org/about/picker-principles/

12. National Institute for Health and Care Excellence. (2012). Quality standard for patient experience in adult NHS services. Retrieved September 2, 2014, from National Institute for Health and Care Excellence: http://publications.nice.org.uk/qualitystandard-for-patient-experience-in-adult-nhs-servicesqs15

13. World Health Organization. (2000). The World health report 2000 : health systems : improving performance. Geneva: World Health Organization.

14. Nolan, M. R., Brown, J., Davies, S., Nolan, J., \& Keady, J. (2006). The Senses Framework: improving care for older people through a relationship-centred approach. Getting Research into Practice (GRiP) Report No 2. Project Report. Sheffield: University of Sheffield.

15. Jabine, T. B., Straf, M. L., Tanur, J. M., \& Tourangeau, R. (1984). Cognitive sciences and survey methods. In Cognitive Aspects of Survey Methodology: Building a Bridge Between Disciplines (pp. 73-100). Washington DC: National Academy Press.

16. Reeves R, West E, Barron D. Facilitated patient experience feedback can improve nursing care: a pilot study for a phase III cluster randomised controlled trial. BMC Health Serv Res. 2013 Jul 4: 13:259

17. Dillman, D. A., Smyth, J. D., \& Christian, L. M. (2014). Internet, Phone, Mail, and Mixed-Mode Surveys: The Tailored Design Method (4th ed.). Wiley.

18. Barron, D. N., West, E., Reeves, R., \& Hawkes, D. (2014, April). It takes patience and persistence to get negative feedback about patients' experiences: a secondary analysis of national inpatient survey data. BMC Health Services Research, 14(153). doi:10.1186/1472-6963-14-15 